\title{
La investigación en el currículo de las carreras de grado.
}

\section{Research in the curriculum of degree courses.}

Hoy, el mundo moderno no solo exige competitividad, sino también la capacidad de adaptarse a los cambios sociales, tecnológicos y, fundamentalmente, participar en la generación de nuevo conocimiento. El modelo educativo tradicional en Argentina ha enfocado la educación médica hacia el desarrollo del conocimiento médico científico, destrezas y actitudes, poniendo énfasis a la educación clínica-asistencial y dejando relegada la formación en el terreno de la investigación clínica y ciencias básicas.

La Universidad, por definición, representa el centro donde se crea el nuevo conocimiento, las nuevas técnicas y los avances para el mejoramiento de su entorno, y por lo tanto, no debería limitarse a generar profesionales llenos de conceptos, sino con un pensamiento crítico, tanto clínico como investigativo, dando forma a la integralidad del razonamiento médico por excelencia. Más allá de su rol en la formación holística del profesional, la investigación desempeña también un rol de vinculación entre la Universidad y la sociedad.

Actualmente, la investigación y la producción científica de las instituciones académicas constituyen una medida relevante de su calidad, es el sustrato por el que se mide el impacto de las universidades tanto a nivel local, como internacional. Consiguientemente, la Universidad debería preparar e instruir a sus pre-graduandos en la generación de conocimiento mediante la investigación científica.

El gran desafío para las escuelas de Medicina es reflexionar sobre la reforma de los currículos en investigación en el pregrado, identificando a la misma como un pilar en el desarrollo y vínculo genuino con la asistencia y la docencia. Los académicos debemos concebir al estudiante como un investigador en potencia desde el inicio de su carrera e inculcar en todo el proceso formativo una conducta de investigación que les permita aprender por sí mismo y a generar nuevo conocimiento. En este sentido, a través de la innovación educativa, se busca cambiar el enfoque de enseñanza; de estar "centrada en el profesor" a "centrada en el estudiante", lo cual incluye el aprendizaje basado en la resolución de problemas, el currículo orientado hacia la comunidad y la incorporación temprana al laboratorio de investigación básica o médica-antropológica , con un objetivo académico fundamental: dejar de considerar al estudiante un simple consumidor de información para identificarlo también como creador de esa información médica. Además, durante mucho tiempo, la enseñanza de metodología de la investigación en la Carrera de Medicina se ha realizado mediante la comunicación de recetas tales como plantear problemas, identificar variables, plantear hipótesis, analizar datos, etc.; este enfoque es, por cierto, más informativo que formativo. Por el contrario, tanto la formación para la investigación como la investigación formativa debiese ser un eje fundamental a lo largo de toda la carrera de pregrado a través del desarrollo de competencias investigativas estimulando el pensamiento analítico, reflexivo, crítico y meta cognitivo. 


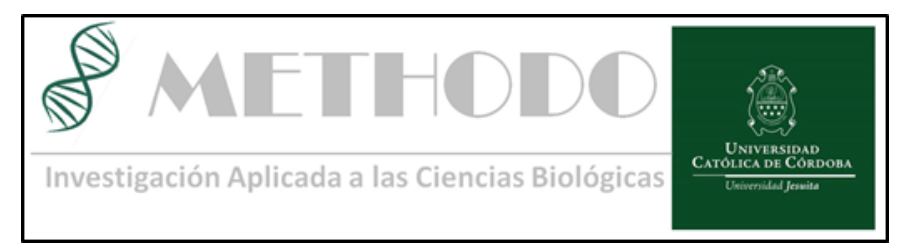

Saenz FC. La investigación en el currículo de las carreras de grado Editorial Methodo 2018;03(1):01-03

En la actualidad, los espacios curriculares y extracurriculares para el desarrollo de investigación no son suficientes, entre otras razones, por la saturación de asignaturas en los planes de estudio. Otro factor importante a considerar es la ausencia de integración, la desvinculación o la división entre docencia e investigación, con la convicción errónea de que la investigación solo debe abordarse exclusivamente en las asignaturas de esta área.

Por su parte, existen tres mecanismos por los cuales el estudiante se vincula con la investigación: obligatoria, optativa y extracurricular. La primera, como parte de un curso que forma parte de su currículo; optativa, donde el estudiante decide si quiere o no llevar el curso; y extracurricular, que es la gran mayoría de los casos, donde el estudiante realiza o participa de una investigación, sin tener ninguna obligación, sólo por el deseo innato de investigar. En Alemania, por ejemplo, los estudiantes de Medicina tienen como requisito para obtener el título médico haber realizado investigación durante el pregrado. Las estadísticas muestran que alrededor del $70 \%$ de los estudiantes realizan sus trabajos de investigación (tesis) durante la carrera o en el internado. En otros países desarrollados como Estados Unidos o Gran Bretaña, la investigación del estudiante suele ser opcional. En Argentina, como en Latinoamérica, la actividad de investigación es escasa; países como México y Brasil son los de mayor producción científica.

El tema investigación en la formación universitaria se debe abordar desde la práctica de la investigación, práctica que se manifiesta de dos maneras: aprender a investigar y aprender investigando. La primera hace referencia al ejercicio de la docencia investigativa, es decir utilizar la investigación en la docencia. La segunda se refiere a la producción de conocimiento y su aplicación para resolver problemas del contexto. Es por esta razón que, en el desarrollo o renovación de una malla curricular se debe definir el enfoque investigativo, proponiendo a la investigación como parte de un proceso educativo universitario y no necesariamente como una iniciativa propia, es decir formando parte de los grandes núcleos de objetivos académicos junto a las ciencias básicas, clínicas y salud comunitaria.

En necesario reconocer que el estudiante es un investigador desde que inicia su carrera y que la investigación se hace en equipo. Es importante destacar también que el trabajo en equipo no solo se refiere a trabajar con un grupo de personas, sino con la inclusión de la institución educativa donde realiza el proyecto. Las universidades deben apoyar y estimular los proyectos de investigación que realizan sus estudiantes y bridarles los recursos, tanto humanos, económicos y didáctico-metodológicos, como parte del equipo de trabajo. Para la formación del nuevo investigador, el estudiante debe percibir en el ámbito académico, la cultura y la disciplina investigativa, debe tener una adecuada motivación, con un proceso formativo dirigido por un mentor. En algunas Escuelas de Medicina de Latinoamérica existe una figura denominada semillero de investigación, espacio que propicia la formación del estudiante universitario en áreas como el trabajo colaborativo en donde se desarrollan destrezas en organización, escritura científica, habilidades de laboratorio, como una herramienta cuyo objetivo es promover nuevo talento en áreas investigativas.

Finalmente, la participación del estudiante en la investigación científica propicia un aprendizaje vivencial significativo relacionado con la búsqueda y enriquecimiento del conocimiento. La investigación científica como recurso de aprendizaje posibilita la expresión de las potencialidades creativas del estudiante en el planteamiento de hipótesis y estrategias para la búsqueda de solución científica a los problemas, al mismo tiempo que promueve el desarrollo del interés cognoscitivo y la responsabilidad en la actuación. 


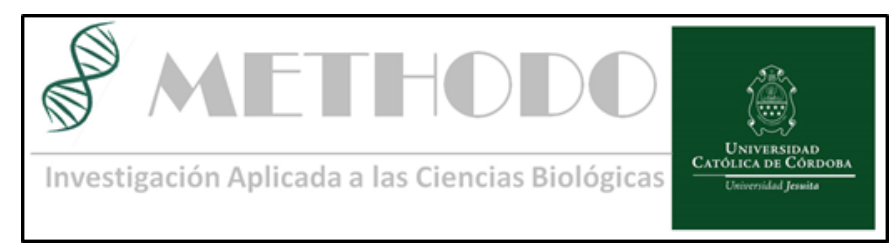

Saenz FC. La investigación en el currículo de las carreras de grado Editorial Methodo 2018;03(1):01-03

Los que formamos parte de las Escuelas de Medicina deberíamos dejar de transitar la educación pasiva, en la que el educando es un espectador-consumidor del conocimiento (aprendiz fugaz), para ingresar a una educación activa, participativa, la que define al papel del alumno como protagonista en la aventura de su propio conocimiento.

Prof. Dr. Fabián C. Saenz

Departamento de Educación Médica

Facultad de Ciencia de la Salud

Universidad Católica de Córdoba

1. Jhony A. De La Cruz-Vargas, María del Socorro Alatrista Gutiérrez Vda. De Bambaren. Investigación formativa en medicina y ciencias de la salud. [Artículo de Revisión].2017;17(3):70-74. DOI 10.25176/RFMH.v17.n3.1070

2. Córdoba, M.E. (2016). Reflexión sobre la formación investigativa de los estudiantes de pregrado. Revista Virtual Universidad Católica del Norte, 47, 20-37. Recuperado de

http://revistavirtual.ucn.edu.co/index.php/RevistaUCN/article/view/740/1266

3. Mauricio José Ávila, Andrea Rodríguez-Restrepo. La importancia de la investigación en el pregrado de medicina. Medwave 2014 Nov;14(10):e6032 doi: 10.5867/medwave.2014.10.6032

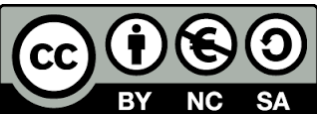

